\title{
Incidence and survival analyses for occult lung cancer between 2004 and 2015: a population-based study
}

\author{
Lei-Lei $\mathrm{Wu}^{1 \dagger}$, Chong-Wu Li ${ }^{1 \dagger}$, Wei-Kang Lin', Li-Hong Qiu ${ }^{2}$ and Dong Xie ${ }^{1 *}$
}

\begin{abstract}
Background: This study aimed to investigate the incidence and long-term survival outcomes of occult lung cancer between 2004 and 2015.

Methods: A total of 2958 patients were diagnosed with occult lung cancer in the 305,054 patients with lung cancer. The entire cohort was used to calculate the crude incidence rate. Eligible 52,472 patients (T1-xNOM0, including 2353 occult lung cancers) were selected from the entire cohort to perform survival analyses after translating T classification according to the 8th TNM staging system. Cancer-specific survival curves for different T classifications were presented.

Results: The crude incidence rate of occult lung cancer was 1.00 per 100 patients, and it was reduced between 2004 and 2015 [1.4 per 100 persons in 2004; 0.6 per 100 persons in 2015; adjusted risk ratio $=0.437$, 95\% confidence interval (CI) 0.363-0.527]. In the survival analysis, there were 2206 death events in the 2353 occult lung cancers. The results of the multivariable analysis revealed that the prognoses with occult lung cancer were similar to patients with stage T3NOMO (adjusted hazard ratio $=1.054,95 \% \mathrm{Cl} 0.986-1.127, p=0.121$ ). Adjusted survival curves presented the same results. In addition, adjusted for other confounders, female, age $\leq 72$ years, surgical treatment, radiotherapy, adenocarcinoma, and non-squamous and non-adenocarcinoma non-small cell carcinoma were independent protective prognostic factors (all $p<0.05$ ).

Conclusions: Occult lung cancer was uncommon. However, the cancer-specific survival of occult lung cancer was poor, therefore, we should put the assessment of its prognoses on the agenda. Timely surgical treatment and radiotherapy could improve survival outcomes for those patients. Besides, we still need more research to confirm those findings.
\end{abstract}

Keywords: Occult lung cancer, Incidence, Survival, Surveillance, Epidemiology, And end results database

\section{Background}

Lung cancer still is the leading malignancy in the global cancer spectrum of morbidity and mortality [1]. Lung cancer mainly comprises non-small cell lung cancer (NSCLC) and small cell lung cancer (SCLC),

\footnotetext{
*Correspondence: kongduxd@163.com

${ }^{\dagger}$ Lei-Lei Wu and Chong-Wu Li contributed equally to this work.

'Department of Thoracic Surgery, Shanghai Pulmonary Hospital, School of Medicine, Tongji University, Shanghai 200433, P. R. China

Full list of author information is available at the end of the article
}

with more than $83 \%$ of all cases being NSCLC [2]. Because of late diagnosis and tumor recurrence, the 5 -year overall survival rate of patients with NSCLC and SCLC remains low (approximately 23 and 6\%, respectively) [2,3]. Tumor proven by the presence of malignant cells in sputum or bronchial washings but not visualized by imaging or bronchoscopy is considered as occult lung cancer $[4,5]$. Previous studies on the incidence of occult lung cancer have only

C C The Author(s). 2021 Open Access This article is licensed under a Creative Commons Attribution 4.0 International License, which permits use, sharing, adaptation, distribution and reproduction in any medium or format, as long as you give appropriate credit to the original author(s) and the source, provide a link to the Creative Commons licence, and indicate if changes were made. The images or other third party material in this article are included in the article's Creative Commons licence, unless indicated otherwise in a credit line to the material. If material is not included in the article's Creative Commons licence and your intended use is not permitted by statutory regulation or exceeds the permitted use, you will need to obtain permission directly from the copyright holder. To view a copy of this licence, visit http://creativecommons.org/licenses/by/4.0/. The Creative Commons Public Domain Dedication waiver (http://creativecommons.org/publicdomain/zero/1.0/) applies to the data made available in this article, unless otherwise stated in a credit line to the data. 
analyzed groups of stroke patients, or incidental case reports of other diseases [6-9]. Therefore, for lung cancer patients, the incidence information of occult lung cancer remains insufficient.

In addition, accurate tumor-lymph node-metastasis (TNM) staging means that the prognosis of the patients is accurate $[10,11]$. Patients with stage IA (classification T1N0M0) have the best long-term survival outcomes in all lung cancers [10]. In the guidelines of the National Comprehensive Cancer Network, occult lung cancers are classified as TxNOMO [12]. Thus, the prognosis of occult lung cancer patients remains unclear because of the unclear TNM classification. The prognoses of diseases have an effect on treatment selection and patients' management. However, there was no data about the incidence rate and survival analyses of occult lung cancer in the previous studies. Thus, we aimed to investigate the incidence rate and prognostic level of those patients with occult lung cancer.

\section{Methods}

\section{Patients}

The Ethics Committee of Shanghai Pulmonary Hospital approved this study and considered this study exempt from ethical review because existing data without patient identifiers were used. This study majorly included two parts, incidence-rate analysis (step 1) and survival analysis (step 2). We retrospectively recruited patients who were histologically diagnosed with malignant tumor in the lungs as their first primary malignancy from 2004 to 2015 in Surveillance, Epidemiology, and End Results (SEER) database, which contains clinicopathological and survival data of cancer patients from 18 registries. Therefore, the present study could be considered as a multi-center analysis. The selection criteria of patients were shown in Fig. 1. A total of 305,054 patients (including 2958 occult lung cancers) were used to perform incidence analysis after step-one case selection. Next, we processed step-two case selection. There were 52,472 eligible patients (including 2353 occult lung cancers) for

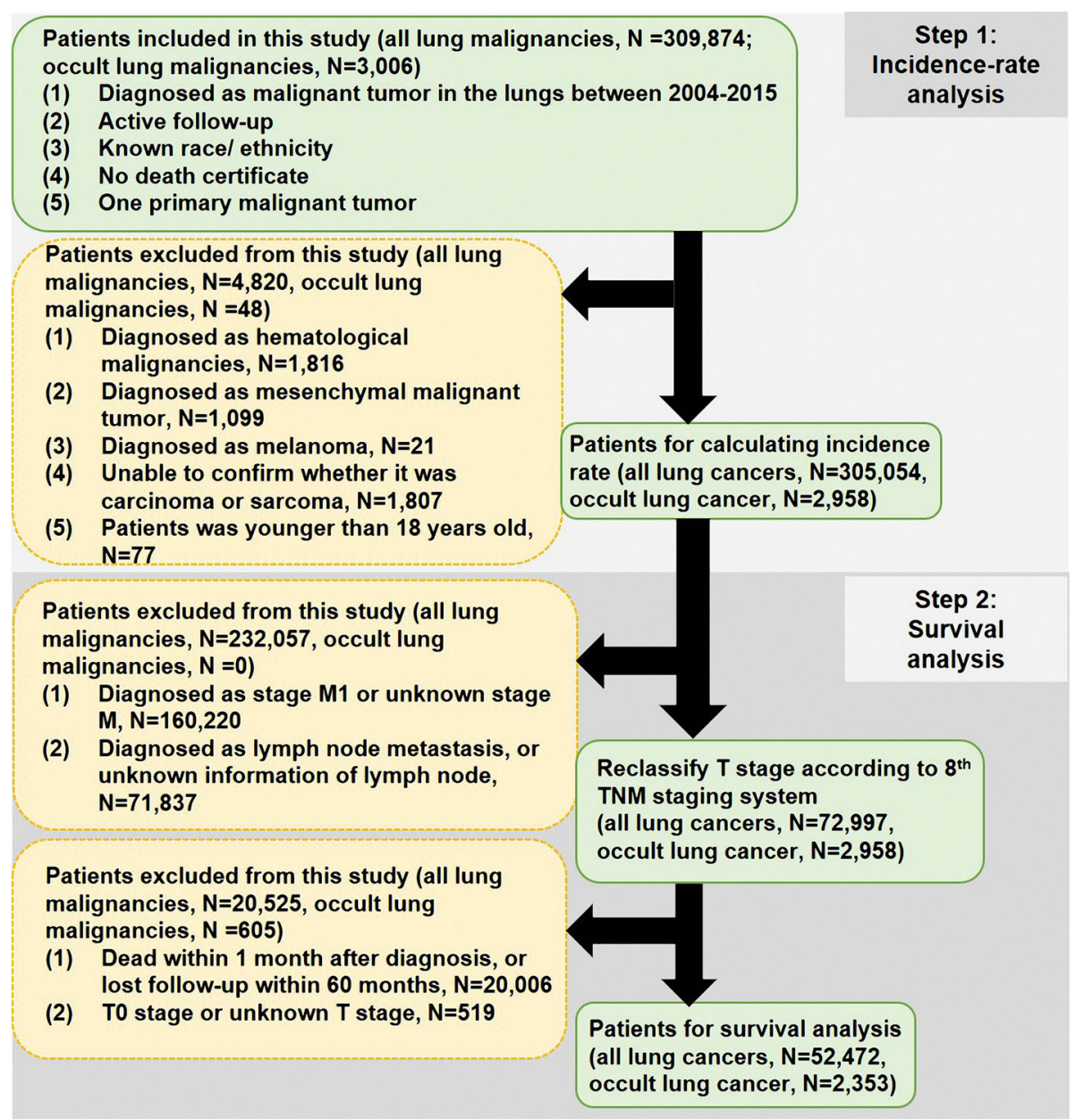

Fig. 1 The flow chart of this study 
survival analysis. The detailed information was presented as Fig. 1. All patient records were anonymized before analysis. Information collected from the SEER database included sex, race/ ethnicity, survival time, cause on disease, age at diagnosis, tumor size, approach of treatment (including surgical treatment, radiotherapy, and chemotherapy), tumor differentiation, histological subtype, tumor location, TNM stage, and marital status.

\section{Follow-up}

Cancer-specific survival, which was the duration from the date of diagnosis to death caused by lung cancer, was regarded as our observational endpoint. For survival analysis, follow-up duration ranged from 1.0 to 155.0 months, with a median of 27.0 months. Those patients who entered the survival analysis had definitive survival status, death or alive.

\section{Statistical analysis}

All statistical analysis was performed using SPSS statistics 25.0 software (IBM SPSS, Inc., Chicago, IL, USA), and GraphPad Prism 8 (https://www.graphpad.com/ scientific-software/prism/). Risk ratios (RRs), hazard ratios (HRs) and 95\% confidence intervals (CIs) were calculated using multivariable Logistic regression analysis and Cox regression analysis, respectively (regression method was Enter selection). The average value of each covariate was calculated by the multivariable Cox regression model, and estimated the adjusted survival curves of $\mathrm{T}$ classification. Statistical tests were considered statistically significant with two-sided $p$ value $<0.05$.

\section{Results}

\section{Patient characteristics}

In the step-one case selection, there were 305,054 patients (including 2958 occult lung cancers) for calculating incidence. Majority of the patients were male $(N=$ $162,448,53.3 \%)$, and 248,125 (81.3\%) were non-Hispanic whites. The median age was 68 years old (range from 18 years to 104 years). The detailed information of patient characteristics was shown in Table 1.

After step-two case selection, eligible 52,472 patients (including 2353 occult lung cancers) entered into processing of survival analysis. Male patients accounted for 51.2\% $(N=26,858)$. Age at diagnosis ranged from 18 years old to 100 years old (median 70 years). The major part of histological subtypes belonged to adenocarcinoma $(N=23,406,44.6 \%)$ as shown in Table 2 .

\section{Incidence-rate analysis}

In the all 305,054 patients, the crude incidence rate was 1.00 per 100 patients, and it was reduced between 2004 and 2015 [Fig. 2, 1.4 (95\% CI 1.22-1.52) per 100 persons in 2004; 0.6 (95\% CI $0.53-0.72)$ per 100 persons in 2015;
Table 3, adjusted $\mathrm{RR}=0.437,95 \%$ CI $0.363-0.527]$. The results of Linear regression revealed that trends about crude incidence rate of occult lung cancer was decreased over time $(\mathrm{R}=0.023, p<0.001)$.

\section{Survival analysis of T classification}

The median survival time of all 52,472 patients was 27 months (range from 1 month to 155 months). Besides, the 1-year, 3-year and 5-year cancer-specific survival rate of this cohort were 62,49 , and $44 \%$, respectively. The unadjusted 5-year cancer-specific survival rate was the best in the patients with $\mathrm{T} 1 \mathrm{a}(75 \%)$ and the worst in the patients with $\mathrm{Tx}(15 \%)$. The median survival time was 13 months (95\% CI 12.10-13.90 months) in the patients with $\mathrm{Tx}$, which indicated the rate of death events had exceeded $50 \%$. We also found that the classification of $\mathrm{Tx}$ was the riskiest factor for the prognoses (Table 4, unadjusted $\mathrm{HR}=6.339, p<0.001)$. However, the results were not inconsistent after multivariable Cox regression analysis. We used multivariable Cox regression analysis to identify the prognostic role of Tx (occult lung cancer) in the different $\mathrm{T}$ classifications (Table 4). After adjusting for other confounders, patients with $\mathrm{Tx}$ had a poorer prognosis than patients of T2b (adjusted HR 1.186, $p<$ 0.001), nevertheless better long-term survival outcomes than patients with T4 (adjusted HR 0.845, $p<0.001$ ). Besides, the prognosis for patients of $\mathrm{Tx}$ was not statistically different from that of T3 patients $(p=0.121)$. The adjusted survival curves also presented similar results (Fig. 3).

\section{Prognostic analysis for occult lung cancer}

There were 2353 occult lung cancer patients for survival analyses, of which baseline characteristics were shown in Table 5. In this cohort, there were 2206 death events in the 2353 occult lung cancers. Female patients showed a better survival than male patients (Table 6, adjusted $\mathrm{HR}=0.796$, 95\%CI 0.726-0.876, $p<0.001)$. Besides, the prognosis in patients with age $>72$ years was poorer than younger patients (adjusted $\mathrm{HR}=1.183$, 95\%CI 1.0631.295). The number of adenocarcinomas was the most, which accounted for $33.0 \%(N=776)$. Its long-term survival outcomes were better than squamous cell carcinomas (adjusted $\mathrm{HR}=0.878, p=0.042$ ). Of note, 1162 patients didn't receive any treatment. However, patients who underwent surgical resection or radiotherapy had improved survival benefits (Table 6). One-hundred and twenty-six patients underwent lobectomy, whose 5-year cancer-specific survival rate reached $47 \%$. After adjusting for other confounders, we identified sex, tumor differentiation, tumor location, age, histological subtypes, radiotherapy, and surgical treatment as independent prognostic factors. 
Table 1 Clinical characteristic of lung cancer patients from Surveillance Epidemiology and End Results database

\begin{tabular}{ll}
\hline Variables & $\begin{array}{l}\text { All patients } \\
(N=305,054)\end{array}$ \\
\hline$N$ & $N$
\end{tabular}

Sex

Male

162,448

Female

142,606

Race

Non-Hispanic whites

248,125

Non-Hispanic others

56,929

Age (year)

$\leq 68$

159,281

$>68$

145,773

Median (range)

68 (18-104)

z Grade

Well

16,073

Moderate

52,350

Poor

85,221

Undifferentiated

14,184

Unknown

13,7226

Tumor Location

Main bronchus

15,819

5.2

Upper lobe

155,796

Middle lobe

13,314

4.4

Lower lobe

77,101

25.3

Overlapping lesion of lung

3973

1.2

Unknown

39,051

Radiotherapy

No

174,025

Yes

128,452

Unknown

2577

\section{Chemotherapy}

Yes

145,867

Marital status

Non-married

Unknown

\section{Surgical treatment}

None
Limited resection
Lobectomy
Pneumonectomy
Unknown surgical approach
Unknown


Table 1 Clinical characteristic of lung cancer patients from Surveillance Epidemiology and End Results database (Continued)

\begin{tabular}{lll}
\hline & $\begin{array}{l}\text { All patients } \\
(\boldsymbol{N}=\mathbf{3 0 5 , 0 5 4 )}\end{array}$ \\
\hline Year at diagnosis & & \\
2004 & 23,625 & 7.7 \\
2005 & 22,774 & 7.6 \\
2006 & 24,250 \\
2007 & 25,094 \\
2008 & 25,384 \\
2009 & 25,936 \\
2010 & 25,606 \\
2011 & 25,631 \\
2012 & 26,120 & 8.2 \\
2013 & 26,344 \\
2014 & 26,874 \\
2015 & 27,416 & 8.3 \\
Occult lung cancer & & 8.4 \\
Yes & 8.4 \\
No & 2958 & 8.6 \\
\hline
\end{tabular}

\section{Discussion}

In the present study, we used the data of 305,054 patients (including 2958occult lung cancer patients) to perform incidence-rate analysis. The results revealed that the crude incidence rate of occult lung cancer was 1.00 per 100 patients, and the incidence-rate trend over time was likely to be reduced between 2004 and 2015 . Next, data on 52,472 eligible patients were analyzed by Cox regression analysis including univariable and multivariable analyses. Those patients included 2353 cases of occult lung cancer. According to the results, we found that occult lung cancer patients didn't have satisfactory survival outcomes. The prognosis of occult lung cancer was between T2b's and T4's. Besides, there was no significant difference in the prognosis of patients with T3 classification or occult lung cancer. After adjusting for other confounders, the female, age $\leq 72$, well differentiation, adenocarcinoma, radiotherapy, and surgical resection were considered as independent protective prognostic factors for 2353 occult lung cancer patients. Therefore, we suggested that surgery might be an appropriate option for occult lung cancer.

The incidence rate of occult lung cancer varied to a certain extent in the different populations. Previous studies and case reports found that occult lung cancer was usually accompanied by symptoms, metastatic diseases or other internal-medicine diseases when it was detected [6, 13-16]. Yoel Siegel et al. described a case report that occult lung cancer could mimic pneumonia and a pulmonary embolus by occluding a pulmonary vein [7]. A case by William Carrera et al. presented that occult small cell lung cancer might have a relation with occurring of retinopathy with chorioretinitis and optic neuritis [8]. Besides, Hui Mai et al. performed a study about characteristics of occult lung cancer-associated ischemic stroke, and suggested that occult cancer should be considered in the setting of multiple and recurrent embolic strokes within the short term in the absence of conventional stroke etiologies [9]. The above cases and study showed that occult lung cancer might be accompanied by different clinical symptoms. However, clinicians tend to pay more attention to their specialties, thus the diagnosis of the occult lung cancer becomes more complicated. Therefore, the research on the incidence rate of this disease may provide clinicians with some references for disease diagnosis and treatment.

Because malignant tumors may cause the blood to hypercoagulable state, which leads to the occurrence of thrombosis [17], the previous researchers began to investigate the incidence of occult lung cancer in stroke patients. Alejandro Daniel Babore et al. analyzed data of over 800,000 patients, and uncovered that the prevalence of occult lung cancer was 5.3 per 1000 patients in the stroke patients, and 2.6 per 1000 patients in the control group [6]. The sample size of their study was large, therefore, the results had clinical reference value. However, the results of the present study revealed that crude incidence rate of occult lung cancer was 10.0 per 1000 patients, which was much higher than the findings from above study. This difference in the incidence-rate results 
Table 2 Clinicopathological characteristic of lung cancer patients for survival analysis

\begin{tabular}{|c|c|c|}
\hline & $\begin{array}{l}\text { All patients } \\
(N=52,472)\end{array}$ & \\
\hline Variables & $N$ & $\%$ \\
\hline \multicolumn{3}{|l|}{ Sex } \\
\hline Male & 26,858 & 51.2 \\
\hline Female & 25,614 & 48.8 \\
\hline
\end{tabular}

\section{Race}

Non-Hispanic whites

Non-Hispanic others

\section{Age (year)}

$\leq 68$

$>68$

Median (range)

\section{Grade}

Well

Moderate

Poor

Undifferentiated

Unknown

\section{Tumor Location}

Main bronchus

Upper lobe

Middle lobe

Lower lobe

Overlapping lesion of lung

Unknown

\section{Radiotherapy}

No

Yes

Unknown

\section{Chemotherapy}

No

Yes

\section{Marital status}

\author{
Married \\ Non-married
}

Unknown

\section{Surgical treatment}

None
Limited resection
Lobectomy
Pneumonectomy
Unknown surgical approach
Unknown

43,818

8654

23,070

44.0

29,402

56.0

70 (18-100)

5579

10.6

16,142

30.8

16,855

32.1

1745

3.3

12,151

23.2

1271

2.4

30,463

58.0

2423

4.6

15,734

30.0

607

1.2

1974

3.8

37,612

71.7

14,508

352

0.7

39,127

74.6

13,345

8

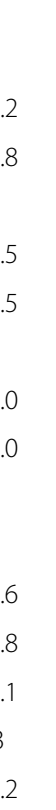

4

.

0

\section{.7}

7


Table 2 Clinicopathological characteristic of lung cancer patients for survival analysis (Continued)

\begin{tabular}{|c|c|c|}
\hline & $\begin{array}{l}\text { All patients } \\
(N=52,472)\end{array}$ & \\
\hline \multicolumn{3}{|l|}{ Histological subtypes } \\
\hline Squamous cell carcinoma & 16,691 & 31.8 \\
\hline Adenocarcinoma & 23,406 & 44.6 \\
\hline Non-squamous and non-adenocarcinoma NSCLC & 5128 & 9.8 \\
\hline Small-cell carcinoma & 2583 & 4.9 \\
\hline Unknown non-sarcoma carcinoma & 477 & 0.9 \\
\hline Unknown NSCLC & 4187 & 8.0 \\
\hline \multicolumn{3}{|l|}{ T classification } \\
\hline T1a & 1752 & 3.3 \\
\hline $\mathrm{T} 1 \mathrm{~b}$ & 9439 & 18.0 \\
\hline $\mathrm{T} 1 \mathrm{c}$ & 8412 & 16.1 \\
\hline T2a & 11,509 & 21.9 \\
\hline $\mathrm{T} 2 \mathrm{~b}$ & 3784 & 7.2 \\
\hline T3 & 4180 & 8.0 \\
\hline T4 & 11,043 & 21.0 \\
\hline Tx (occult) & 2353 & 4.5 \\
\hline
\end{tabular}

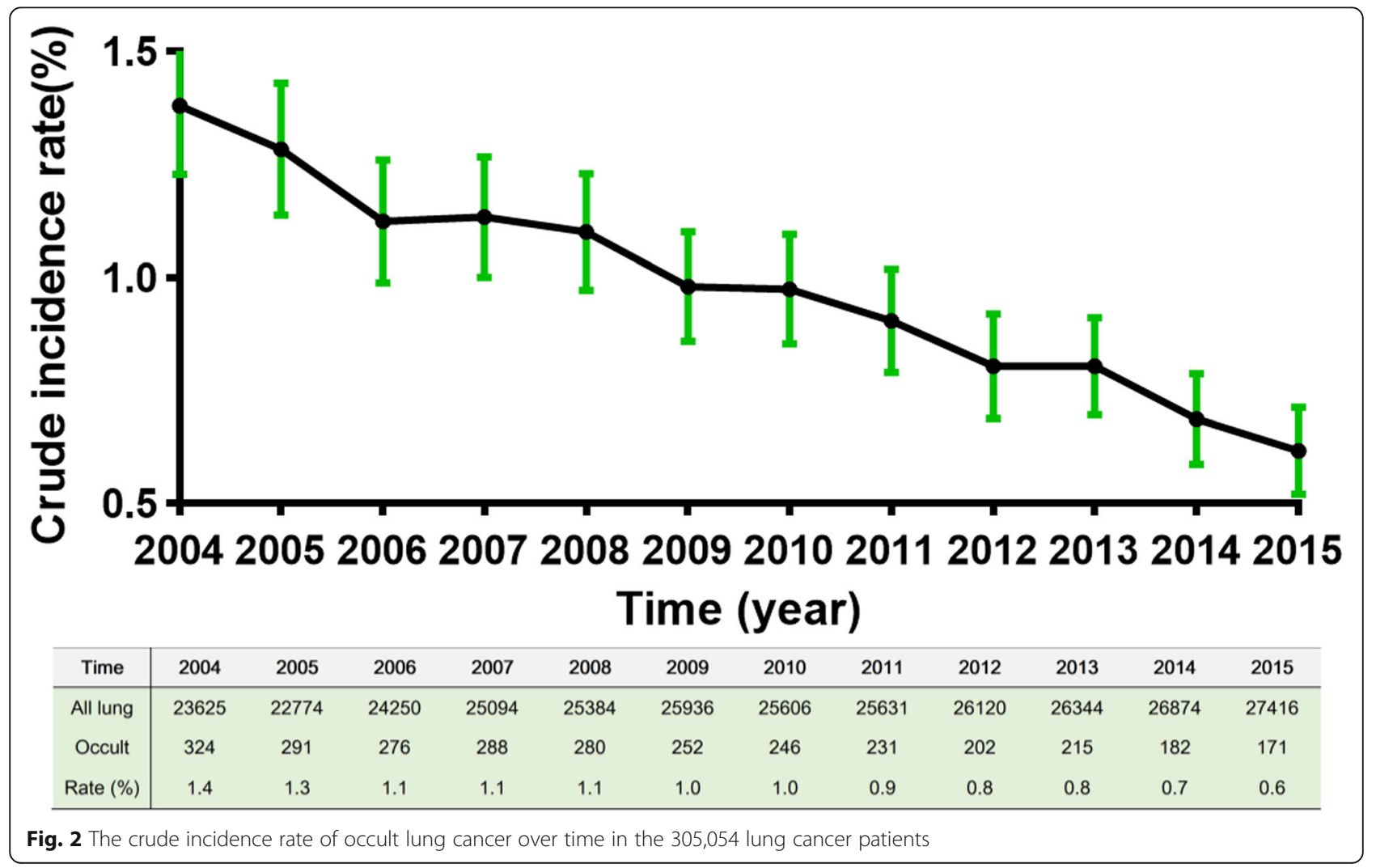


Table 3 The results of multivariable Logistic regression analyses

\begin{tabular}{llll}
\hline & \multicolumn{3}{l}{ Multivariable analysis } \\
\cline { 2 - 4 } & RR & $\mathbf{9 5 \%}$ Cl & P-Value \\
\hline Year at diagnosis & & & \\
2004 & & reference & \\
2005 & 0.927 & $0.790-1.087$ & 0.349 \\
2006 & 0.828 & $0.705-0.974$ & 0.022 \\
2007 & 0.828 & $0.706-0.972$ & 0.021 \\
2008 & 0.792 & $0.674-0.930$ & 0.005 \\
2009 & 0.696 & $0.589-0.821$ & $<0.001$ \\
2010 & 0.685 & $0.580-0.809$ & $<0.001$ \\
2011 & 0.643 & $0.543-0.762$ & $<0.001$ \\
2012 & 0.549 & $0.460-0.655$ & $<0.001$ \\
2013 & 0.578 & $0.486-0.687$ & $<0.001$ \\
2014 & 0.479 & $0.399-0.575$ & $<0.001$ \\
2015 & 0.437 & $0.363-0.527$ & $<0.001$ \\
Sex & & & \\
Male & 1 & reference & \\
Female & 0.988 & $0.919-1.063$ & 0.752 \\
Age (continuous) & 1.035 & $1.031-1.038$ & $<0.001$ \\
Race & & & \\
Non-Hispanic whites & 1 & reference & \\
Non-Hispanic others & 0.925 & $0.842-1.016$ & \\
\hline & & &
\end{tabular}

$R R$ risk ratio, $\mathrm{Cl}$ confidence interval

Logistic regression's method was Enter selection

The results of multivariable analysis were adjusted for other confounding

factors, such as sex, age, and race/ ethnicity between above two studies was likely to be due to different selected cohorts. Our study cohort focused on lung cancer, which led to a higher incidence rate of occult lung cancer in the present study. However, the study by Alejandro Daniel Babore et al. majorly compared the incidence rate of occult lung cancer in stoke patients with that in general patients. Besides, they tried to explore the factors which might have effect on incidence rate. Though, this present study paid more attention to the incidence rate of occult lung cancer in entire lung cancer cohort, and illustrated that the incidence rate over time was reduced between 2004 and 2015. The reason why general trend over time was declined might be the popularization of computed tomography screening and the promotion of bronchoscopy $[4,18,19]$.

The present study found that the prognosis of occult lung cancer patients was poorer than that in patients with T2 disease. Those patients might have occult metastasis of lymph node or another organ, which leads to a poor prognosis. Of note, timely therapy could improve the long-term survival in the occult lung cancer. Patients who underwent surgical resection had better cancerspecific survival than patients who didn't receive surgical treatment. And, the best survival benefit was derived from lobectomy. Joel J. Bechtel et al. and Cortese DA et al. had similar findings in their research [20, 21]. They suggested that 5 -year survival rate was 74 and $90 \%$ in patients with cure resection, respectively. However, the sample size was relatively small in their research [20, 21]. For example, in the study by Joel J. Bechtel et al.,

Table 4 Univariable and multivariable Cox regression analyses for prognostic factors

\begin{tabular}{|c|c|c|c|c|c|c|c|}
\hline & \multirow[t]{2}{*}{$\mathbf{N}$} & \multirow{2}{*}{$\begin{array}{l}5- \\
\text { year } \\
\text { CSS }\end{array}$} & \multicolumn{2}{|c|}{ Univariable analysis } & \multicolumn{3}{|c|}{ Multivariable analysis } \\
\hline & & & HR & $P$-Value & HR & $95 \% \mathrm{Cl}$ & $P$-Value \\
\hline T classification & & & & $<0.001$ & & & $<0.001$ \\
\hline T1a & 1752 & $75 \%$ & 1 & & 1 & reference & \\
\hline T1b & 9439 & $67 \%$ & 1.230 & $<0.001$ & 1.113 & $1.010-1.227$ & 0.030 \\
\hline T1c & 8412 & $56 \%$ & 1.788 & $<0.001$ & 1.379 & $1.252-1.519$ & $<0.001$ \\
\hline $\mathrm{T} 2 \mathrm{a}$ & 11,509 & $47 \%$ & 2.345 & $<0.001$ & 1.889 & $1.719-2.076$ & $<0.001$ \\
\hline $\mathrm{T} 2 \mathrm{~b}$ & 3784 & $37 \%$ & 3.079 & $<0.001$ & 2.172 & $1.964-2.402$ & $<0.001$ \\
\hline T3 & 4180 & $31 \%$ & 3.759 & $<0.001$ & 2.510 & $2.273-2.772$ & $<0.001$ \\
\hline T4 & 11,043 & $19 \%$ & 5.555 & $<0.001$ & 3.178 & $2.892-3.493$ & $<0.001$ \\
\hline Tx (occult) & 2353 & $15 \%$ & 6.344 & $<0.001$ & 2.624 & $2.365-2.910$ & $<0.001$ \\
\hline \multicolumn{8}{|c|}{ Subgroup comparison } \\
\hline Tx vs. T2b & - & - & 2.020 & $<0.001$ & 1.186 & $1.104-1.273$ & $<0.001$ \\
\hline Tx vs. T3 & - & - & 1.648 & $<0.001$ & 1.054 & $0.986-1.127$ & 0.121 \\
\hline Tx vs. T4 & - & - & 1.127 & $<0.001$ & 0.845 & $0.801-0.891$ & $<0.001$ \\
\hline
\end{tabular}

$H R$ hazard ratio, $\mathrm{Cl}$ confidence interval

Cox regression's method was Enter selection

The results of multivariable analysis were adjusted for other confounding factors, such as sex, age, tumor differentiation, radiotherapy, chemotherapy, surgical treatment, histological subtypes, marital status, tumor location and race/ ethnicity 


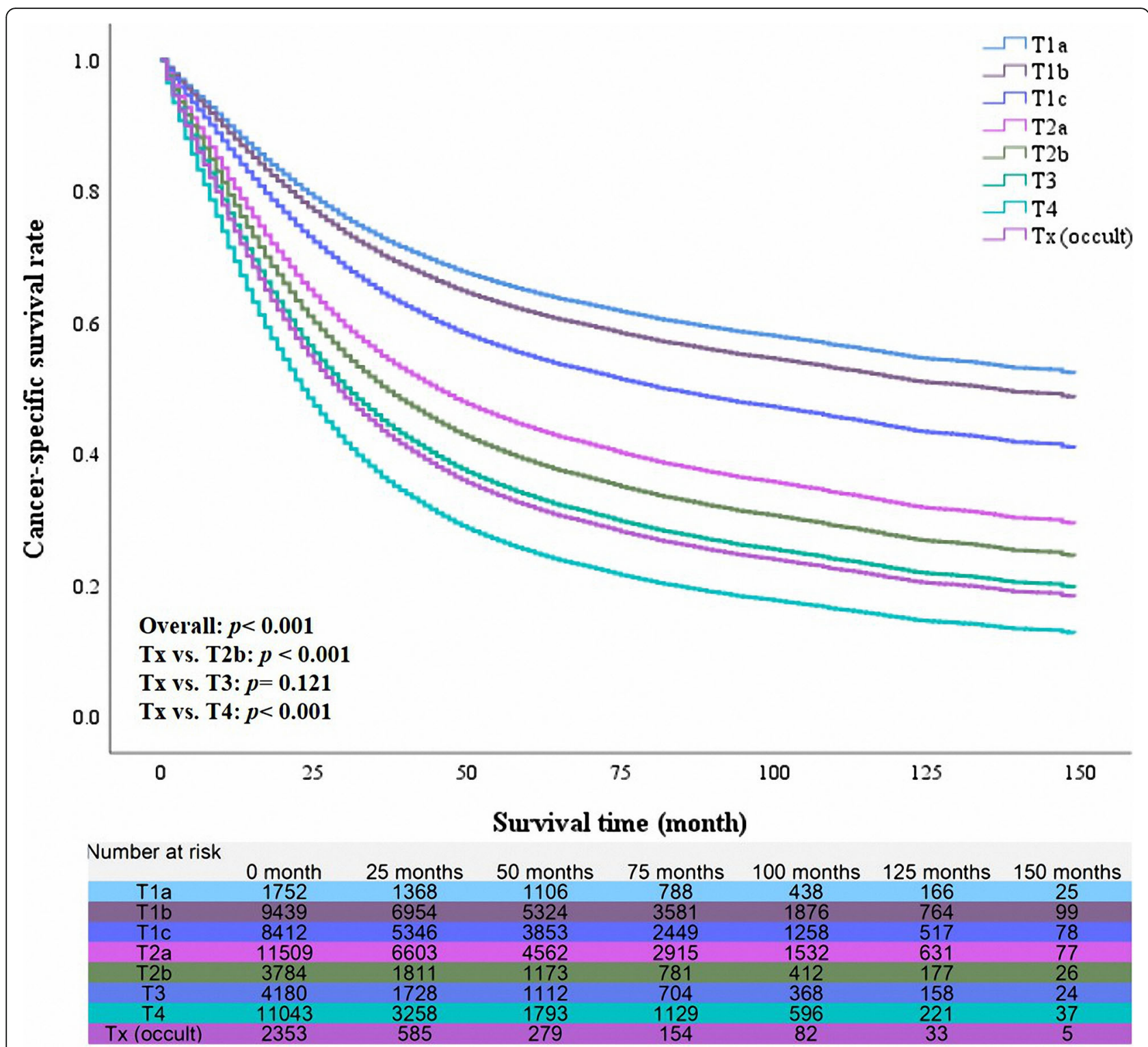

Fig. 3 The adjusted survival curves of different $T$ classifications

only 27 of the 51 patients they enrolled underwent surgical resection. Similarly, there were only 54 patients underwent operation in the study by Cortese $D A$ et al. The sample size of the present study was different from above mentioned studies causing the difference of 5-year survival rate followed surgical resection. Besides, radiotherapy was proven to have survival benefit in the 71case study by $M$ Saito et al [22]. In the present study, compared with patients who didn't receive radiotherapy, cases with radiotherapy had a better survival. These findings confirmed the results from previous study.

This study has several limitations. First, some important information (such as the invasion depth of tumor in the endobronchial wall) wasn't detailed, as we couldn't obtain the results of bronchoscopy and radiology in the SEER database. Thus, we did not further categorize the Tx classification. Second, cases with second primary lung cancer were excluded from the study. However, the incidence rate of occult lung cancer might be much higher in the cohort of second primary lung cancer. Therefore, the use of those findings was limited to patients with primary lung cancer. Third, because the data on histological subtypes were not detailed enough, unknown non-sarcoma cancer and unknown non-small cell carcinoma couldn't be subdivided. Finally, this study belonged to retrospective study. Therefore, more studies are necessary to further explore the incidence rate and prognosis in patients with occult lung cancer. 
Table 5 Baseline characteristics in the cohort with occult lung cancer

\begin{tabular}{|c|c|c|}
\hline Variables & $\begin{array}{l}\text { All patients } \\
(N=2353)\end{array}$ & Percentage (\%) \\
\hline \multicolumn{3}{|l|}{ Sex } \\
\hline Male & 1235 & 52.5 \\
\hline Female & 1118 & 47.5 \\
\hline \multicolumn{3}{|l|}{ Tumor differentiation } \\
\hline Well & 186 & 7.9 \\
\hline Moderate & 409 & 17.4 \\
\hline Poor & 686 & 29.1 \\
\hline Unknown & 1072 & 45.6 \\
\hline \multicolumn{3}{|l|}{ Tumor location } \\
\hline Upper lobe & 1096 & 46.6 \\
\hline Middle lobe & 105 & 4.5 \\
\hline Lower lobe & 668 & 28.4 \\
\hline Other location & 105 & 4.5 \\
\hline Unknown & 379 & 16.0 \\
\hline \multicolumn{3}{|l|}{ Age (year) } \\
\hline$\leq 72$ & 1210 & 51.4 \\
\hline$>72$ & 1143 & 48.6 \\
\hline Median (range) & $72(19-99)$ & \\
\hline \multicolumn{3}{|l|}{ Histological subtypes } \\
\hline Squamous cell carcinoma & 726 & 30.9 \\
\hline Adenocarcinoma & 776 & 33.0 \\
\hline Non-squamous and non-adenocarcinoma NSCLC & 165 & 7.0 \\
\hline Small-cell carcinoma & 300 & 12.7 \\
\hline Unknown non-sarcoma carcinoma & 55 & 2.3 \\
\hline Unknown NSCLC & 331 & 14.1 \\
\hline \multicolumn{3}{|l|}{ Chemotherapy } \\
\hline No & 1677 & 71.3 \\
\hline Yes & 676 & 28.7 \\
\hline \multicolumn{3}{|l|}{ Radiotherapy } \\
\hline No & 1703 & 72.4 \\
\hline Yes & 623 & 26.5 \\
\hline Unknown & 27 & 1.1 \\
\hline \multicolumn{3}{|l|}{ Marital status } \\
\hline Married & 1092 & 46.4 \\
\hline Non-married & 1116 & 47.4 \\
\hline Unknown & 145 & 6.2 \\
\hline \multicolumn{3}{|l|}{ Race/ ethnicity } \\
\hline Non-Hispanic whites & 1928 & 81.9 \\
\hline Non-Hispanic other & 425 & 18.1 \\
\hline \multicolumn{3}{|l|}{ Surgical treatment } \\
\hline None & 2077 & 88.3 \\
\hline Limited resection & 77 & 3.3 \\
\hline Lobectomy & 126 & 5.4 \\
\hline Pneumonectomy & 7 & 0.3 \\
\hline Unknown surgical approach & 4 & 0.2 \\
\hline Unknown & 62 & 2.5 \\
\hline
\end{tabular}


Table 6 Univariable and multivariable Cox proportional hazard regression analyses for prognostic factors in 2353 occult lung cancer patients

\begin{tabular}{|c|c|c|c|c|c|c|}
\hline \multirow{2}{*}{$\begin{array}{l}\text { Variables } \\
\end{array}$} & \multirow{2}{*}{$\begin{array}{l}5- \\
\text { year } \\
\text { CSS }\end{array}$} & \multicolumn{2}{|c|}{ Univariable analysis } & \multicolumn{3}{|c|}{ Multivariable analysis } \\
\hline & & $\mathrm{HR}$ & $P$-Value & $\mathrm{HR}$ & $95 \% \mathrm{Cl}$ & $P$-Value \\
\hline \multicolumn{7}{|l|}{ Sex } \\
\hline Male & $14 \%$ & 1 & & 1 & reference & \\
\hline Female & $16 \%$ & 0.830 & $<0.001$ & 0.796 & $0.723-0.876$ & $<0.001$ \\
\hline \multicolumn{7}{|l|}{ Tumor differentiation } \\
\hline Well & $18 \%$ & 1 & & 1 & reference & \\
\hline Moderate & $17 \%$ & 1.062 & 0.564 & 0.654 & $0.769-1.179$ & 0.654 \\
\hline Poor & $13 \%$ & 1.373 & 0.001 & 1.214 & $1.003-1.506$ & 0.046 \\
\hline Unknown & $15 \%$ & 1.152 & 0.131 & 1.038 & $0.860-1.264$ & 0.669 \\
\hline \multicolumn{7}{|l|}{ Tumor location } \\
\hline Upper lobe & $17 \%$ & 1 & & 1 & reference & \\
\hline Middle lobe & $9 \%$ & 1.090 & 0.447 & 1.141 & $0.913-1.427$ & 0.246 \\
\hline Lower lobe & $14 \%$ & 1.110 & 0.067 & 1.124 & $1.004-1.259$ & 0.042 \\
\hline Other location & $18 \%$ & 1.115 & 0.354 & 1.036 & $0.822-1.305$ & 0.767 \\
\hline Unknown & $11 \%$ & 1.291 & $<0.001$ & 1.241 & $1.084-1.421$ & 0.002 \\
\hline \multicolumn{7}{|l|}{ Age (median, year) } \\
\hline$\leq 72$ & $16 \%$ & 1 & & 1 & reference & \\
\hline$>72$ & $14 \%$ & 1.237 & $<0.001$ & 1.183 & $1.072-1.305$ & 0.001 \\
\hline \multicolumn{7}{|l|}{ Histological subtypes } \\
\hline Squamous cell carcinoma & $13 \%$ & 1 & & 1 & reference & \\
\hline Adenocarcinoma & $14 \%$ & 0.890 & 0.05 & 0.878 & $0.775-0.995$ & 0.042 \\
\hline Non-squamous and non-adenocarcinoma NSCLC & $24 \%$ & 0.680 & $<0.001$ & 0.754 & $0.609-0.933$ & 0.010 \\
\hline Small-cell carcinoma & $12 \%$ & 0.992 & 0.920 & 0.958 & $0.812-1.131$ & 0.616 \\
\hline Unknown non-sarcoma carcinoma & $31 \%$ & 0.647 & 0.022 & 0.558 & $0.380-0.820$ & 0.003 \\
\hline Unknown NSCLC & $15 \%$ & 0.952 & 0.518 & 0.923 & $0.790-1.079$ & 0.317 \\
\hline \multicolumn{7}{|l|}{ Chemotherapy } \\
\hline No & $17 \%$ & 1 & & 1 & reference & \\
\hline Yes & $10 \%$ & 0.926 & 0.132 & 0.946 & $0.846-1.059$ & 0.338 \\
\hline \multicolumn{7}{|l|}{ Radiotherapy } \\
\hline No & $15 \%$ & 1 & & 1 & reference & \\
\hline Yes & $16 \%$ & 0.795 & $<0.001$ & 0.716 & $0.638-0.802$ & $<0.001$ \\
\hline Unknown & $12 \%$ & 1.077 & 0.730 & 1.020 & $0.666-1.562$ & 0.928 \\
\hline \multicolumn{7}{|l|}{ Marital status } \\
\hline Non-married & $14 \%$ & 1 & & & & \\
\hline Married & $15 \%$ & 0.990 & 0.837 & & & \\
\hline Unknown & $17 \%$ & 1.045 & 0.662 & & & \\
\hline \multicolumn{7}{|l|}{ Race/ ethnicity } \\
\hline Non-Hispanic whites & $15 \%$ & 1 & & 1 & reference & \\
\hline Non-Hispanic other & $16 \%$ & 0.995 & 0.938 & 1.063 & $0.941-1.202$ & 0.323 \\
\hline \multicolumn{7}{|l|}{ Surgical treatment } \\
\hline None & $12 \%$ & 1 & & 1 & reference & \\
\hline Limited resection & $30 \%$ & 0.462 & $<0.001$ & 0.476 & $0.354-0.640$ & $<0.001$ \\
\hline Lobectomy & $47 \%$ & 0.285 & $<0.001$ & 0.269 & $0.269-0.352$ & $<0.001$ \\
\hline Pneumonectomy & $13 \%$ & 0.476 & 0.098 & 0.427 & $0.176-1.032$ & 0.059 \\
\hline Unknown surgical approach & NA & 0.506 & 0.238 & 0.544 & $0.175-1.695$ & 0.294 \\
\hline Unknown & $16 \%$ & 0.972 & 0.847 & 0.899 & $0.673-1.203$ & 0.475 \\
\hline
\end{tabular}

$H R$ hazard ratio, $C l$ confidence interval, NSCLC non-small cell lung carcinoma Cox regression's method was Enter selection 


\section{Conclusions}

Occult lung cancer was uncommon. However, the cancer-specific survival of occult lung cancer was poor, therefore, we should put the assessment of its prognoses on the agenda. Timely surgical treatment and radiotherapy could improve survival outcomes. Besides, we still need more research to confirm those findings.

\section{Abbreviations}

NSCLC: Non-small cell lung cancer; SCLC: Small cell lung cancer;

TNM: Tumor-lymph node-metastasis; SEER: Surveillance, Epidemiology, and

End Results; RR: Risk ratio; HR: Hazard ratio; Cl: Confidence interval

\section{Acknowledgments}

We thank all the staff of Surveillance, Epidemiology, and End Results for their contribution in recording medical records. Lei-Lei Wu sincerely thanks Prof. Tie-Hua Rong and Guo-Wei Ma for instructing clinical knowledge, surgery and research in thoracic oncology.

\section{Authors' contributions}

LLW and DX contributed to the study design, data collection, data analyses, data interpretation, and manuscript drafting. LLW, LHQ and CWL contributed to data analyses and manuscript review. WKL, LLW, LHQ, CWL and DX contributed to data interpretation and manuscript review. All authors contributed to the final approval of the manuscript.

\section{Funding}

This study was supported by Shanghai Health Commission (2019SY072), Shanghai ShenKang Hospital Development Centre (SHDC22020218), Outstanding Young Medical Talent of Rising Star in Medical Garden of Shanghai Municipal Health Commission "Dong Xie", and Shanghai Pulmonary Hospital Research Fund (FK18001 \& FKGG1805). The funding bodies played no role in the design of the study and collection, analysis, and interpretation of data and in writing the manuscript. The funding bodies played a role in the interpretation of data, in writing, and in reviewing the manuscript.

\section{Availability of data and materials}

Any researchers interested in this study could contact corresponding author for requiring data.

\section{Declarations}

\section{Ethics approval and consent to participate}

The Ethics Committee of Shanghai Pulmonary Hospital approved this study and considered this study exempt from ethical review because existing data without patient identifiers were used.

\section{Consent for publication}

Not applicable.

\section{Competing interests}

There are no conflicts of interest to declare.

\author{
Author details \\ ${ }^{1}$ Department of Thoracic Surgery, Shanghai Pulmonary Hospital, School of \\ Medicine, Tongji University, Shanghai 200433, P. R. China. ${ }^{2}$ Sun Yat-sen \\ University Cancer Center, State Key Laboratory of Oncology in South China, \\ Collaborative Innovation Center for Cancer Medicine, Guangzhou 510060, P. \\ R. China.
}

Received: 1 June 2021 Accepted: 28 August 2021

Published online: 09 September 2021

\section{References}

1. Bray F, Ferlay J, Soerjomataram I, Siegel RL, Torre LA, Jemal A. Global cancer statistics 2018: GLOBOCAN estimates of incidence and mortality worldwide for 36 cancers in 185 countries. CA Cancer J Clin. 2018;68(6):394-424. https://doi.org/10.3322/caac.21492.
2. Siegel RL, Miller KD, Jemal A. Cancer statistics, 2019. CA Cancer J Clin. 2019; 69(1):7-34. https://doi.org/10.3322/caac.21551.

3. Hung JJ, Jeng WJ, Hsu WH, Huang BS, Wu YC. Time trends of overall survival and survival after recurrence in completely resected stage I nonsmall cell lung cancer. J Thorac Oncol. 2012;7(2):397-405. https://doi.org/1 0.1097/JTO.0b013e31823b564a.

4. Edell ES, Cortese DA. Bronchoscopic localization and treatment of occult lung cancer. Chest. 1989;96(4):919-21. https://doi.org/10.1378/chest.96.4.919.

5. Petty TL, Tockman MS, Palcic B. Diagnosis of roentgenographically occult lung cancer by sputum cytology. Clin Chest Med. 2002;23(1):59-64. https:// doi.org/10.1016/S0272-5231(03)00060-1.

6. Babore AD, Tybjerg AJ, Andersen KK, Olsen TS. Occult lung cancer manifesting within the first year after stroke. J Stroke Cerebrovasc Dis. 2020; 29(9):105023. https://doi.org/10.1016/j.jstrokecerebrovasdis.2020.105023.

7. Siegel Y, Kuker R, Danton G, Gonzalez J. Occult lung Cancer occluding a pulmonary vein with suspected venous infarction, mimicking pneumonia and a pulmonary Embolus. J Emerg Med. 2016;51(2):e11-4. https://doi.org/1 0.1016/j.jemermed.2015.12.019.

8. Carrera W, Tsamis KA, Shah R. A case of cancer-associated retinopathy with chorioretinitis and optic neuritis associated with occult small cell lung cancer BMC Ophthalmol. 2019;19(1):101. https://doi.org/10.1186/s12886-019-1 103-4.

9. Mai H, Xia J, Wu Y, Ke J, Li J, Pan J, et al. Clinical presentation and imaging characteristics of occult lung cancer associated ischemic stroke. J Clin Neurosci. 2015;22(2):296-302. https://doi.org/10.1016/j.jocn.2014.05.039.

10. Rami-Porta R, Asamura H, Travis WD, Rusch WW. Lung cancer - major changes in the American joint committee on Cancer eighth edition cancer staging manual. CA Cancer J Clin. 2017;67(2):138-55. https://doi.org/10.3322/caac.21390.

11. Wu LL. Liu X, Jiang WM, Huang W, Lin P, long $H$, Zhang LJ, ma GW: stratification of patients with stage IB NSCLC based on the 8th edition of the American joint committee on Cancer (AJCC) staging manual. Front Oncol. 2020;10:571. https://doi.org/10.3389/fonc.2020.00571.

12. National Comprehensive Cancer Network. Non-Small Cell Lung Cancer (Version 8.2020, accessed September 15, 2020).

13. Navi BB, DeAngelis $L M$, Segal AZ. Multifocal strokes as the presentation of occult lung cancer. J Neuro-Oncol. 2007;85(3):307-9. https://doi.org/10.1007/ s11060-007-9419-y.

14. Gilardi R, Della Rosa N, Pancaldi G, Landi A. Acrometastasis showing an occult lung cancer. J Plast Surg Hand Surg. 2013;47(6):550-2. https://doi. org/10.3109/2000656X.2012.748319.

15. Han YM, Fang LZ, Zhang XH, Yuan SH, Chen JH, Li YM. Polyarthritis as a prewarning sign of occult lung cancer. Kaohsiung J Med Sci. 2012;28(1):546. https://doi.org/10.1016/j.kjms.2011.06.035.

16. Isohata N, Naritaka Y, Shimakawa T, Asaka S, Katsube T, Konno S, et al. Occult lung Cancer incidentally found during surgery for esophageal and gastric Cancer: a case report. Anticancer Res. 2008;28:1841-8.

17. Dardiotis E, Aloizou AM, Markoula S, Siokas V, Tsarouhas K, Tzanakakis G, et al. Cancer-associated stroke: pathophysiology, detection and management (review). Int J Oncol. 2019:54(3):779-96. https://doi.org/10.3892/ijo.2019.4669.

18. de Koning HJ, van der Aalst CM, de Jong PA, Scholten ET, Nackaerts K, Heuvelmans MA, et al. Reduced lung-Cancer mortality with volume CT screening in a randomized trial. N Engl J Med. 2020;382(6):503-13. https:// doi.org/10.1056/NEJMoa1911793.

19. Sutedja TG, Codrington H, Risse EK, Breuer RH, van Mourik JC, Golding RP, et al. Autofluorescence bronchoscopy improves staging of radiographically occult lung cancer and has an impact on therapeutic strategy. Chest. 2001; 120(4):1327-32. https://doi.org/10.1378/chest.120.4.1327.

20. Bechtel JJ, Petty TL, Saccomanno G. Five year survival and later outcome of patients with $\mathrm{X}$-ray occult lung cancer detected by sputum cytology. Lung Cancer. 2000;30(1):1-7. https://doi.org/10.1016/S0169-5002(00)00190-2.

21. Cortese DA, Pairolero PC, Bergstralh E, Woolner LB, Uhlenhopp MA, Piehler JM, et al. Roentgenographically occult lung cancer. A ten-year experience. J Thorac Cardiovasc Surg. 1983;86(3):373-80. https://doi.org/10.1016/S0022-5223(19)39149-4.

22. Saito M, Yokoyama A, Kurita Y, Uematsu T, Tsukada H, Yamanoi T. Treatment of roentgenographically occult endobronchial carcinoma with external beam radiotherapy and intraluminal low-dose-rate brachytherapy: second report. Int J Radiat Oncol Biol Phys. 2000;47(3):673-80. https://doi.org/10.101 6/S0360-3016(00)00489-2.

\section{Publisher's Note}

Springer Nature remains neutral with regard to jurisdictional claims in published maps and institutional affiliations. 